\title{
SOCIAL SCIENCE RESEARCH NEEDS: A FOCUS ON VULNERABLE POPULATIONS, FORECASTING AND WARNINGS
}

\author{
Brenda D. Phillips, Ph.D. \\ Fire and Emergency Management Program \\ Department of Political Science \\ 519 Math Science Building \\ Oklahoma State University \\ Stillwater OK 74078 \\ 405-744-5298 \\ Brenda.phillips@okstate.edu
}

Betty Hearn Morrow, Ph.D.

Consulting Sociologist

8215 SW 140 Avenue

Miami, FL 33183

305-385-5953

betty@bmorrow.com

\begin{abstract}
This paper assesses the state of social science research specific to populations at risk vis-à-vis weather forecasting and warnings. Populations at risk are defined as groups historically disadvantaged by socio-economic status, patterns of discrimination and/or exclusion, lack of political representation and/or cultural distancing. These contexts marginalize some groups, leaving them less likely to receive, interpret and/or respond appropriately to forecasts and warnings. An overview of key concepts from vulnerability research is provided and research needs emanating from the social science literature relevant to forecasting and warning are suggested.

Written for the Hurricane Forecast Socio-economic Workshop, February 16-18, 2005, Pomona, California.
\end{abstract}




\section{POPULATIONS AT RISK: A STATEMENT OF THE PROBLEM}

Risk communication is a social process that requires receiving, understanding, believing and personalizing the message (Tierney, et al, 2001). The characteristics of the sender and receiver influence the transmission and interpretation of the message, marking the process as a multilayered, culturally-influenced challenge. Uncovering those many layers is the domain of the social sciences working in concert with those delivering messages designed to save lives, reduce injuries and safeguard property. Although the social sciences have made significant contributions to understanding this complex process, many questions remain unanswered.

A number of terms are used to identify those at highest risk such as populations at risk, vulnerable populations, or the socially vulnerable. Underlying each term is the recognition that some citizens face higher risk of injury, death or property loss due to their social or economic circumstances or by virtue of having cultural frameworks or situational locations that are at odds with mainstream society. Two examples are illustrative.

Language can be an important issue in our diverse society. Let's consider the classic study of the Saragosa, Texas tornado where two problems contributed to the loss of life among Spanishspeakers (Aguirre et al. 1987). The first was an incorrect translation of the word "warning" from English into Spanish (Enarson et al. 2004). The second problem occurred because a Spanishlanguage television station did not broadcast local warnings.

Another example of a vulnerable group is the hearing-impaired. With few exceptions (see Wood and Weisman 2002), we lack studies on how deaf persons receive, interpret and disseminate warning messages. A project currently underway by the lead author compares the situation for deaf students in two different colleges located in an area threatened by a tornado. Students and faculty at a school for the deaf sheltered collectively with instructors signing weather information. In contrast, hearing-impaired students at a nearby college left their dormitories to walk to the disability support services office to obtain information, placing them at higher personal risk.

In the example just cited, on-air meteorologists were unable to provide closed-captioning despite a federal order (FCC 00-103) that requires emergency messages to be closed-captioned during extreme weather events. Compounding the problem, broadcast meteorologists often turn their backs to the cameras, preventing those able to read lips from obtaining potentially life-saving information. Finally, it is not sufficient to simply transmit the warning because message content is interpreted within the socio-cultural context of the receiver. As a Gallaudet University student said after assisting the Federal Emergency Management Agency, "it is not just a matter of knowing sign language. It takes years of training to become an interpreter who can work with a group like this, and it takes an understanding of the deaf culture to be effective.”

In short, effective messages containing forecasts, watches and warnings must be considered within the social contexts and cultures of the target populations. Although social science has identified some problems and potential solutions, much remains to be done in this area if we are to achieve our public safety goals for all citizens. 


\section{SOCIAL SCIENCE RESEARCH ON VULNERABLE POPULATIONS: AN ILLUSTRATED OVERVIEW}

Social science research on vulnerable populations has been slow and uneven. It has also tended to focus on one demographic factor, such as age, race and ethnicity, gender or socioeconomic status when in reality a mix of factors probably influences warning receipt and interpretation.

Age. Prior to the 1980's studies rarely mentioned social vulnerabilities with the exception of some examination of the elderly (e.g., see Bell et al. 1978). A few studies during the 1980s cited the risks faced by children albeit with an emphasis on home safety rather than mass disaster (e.g., Peterson et al. 1986 and 1988). More recent studies on the elderly tend to focus on physical disabilities while children's research usually examines at psychological factors. We lack information on how children may or may not access, interpret and respond to forecasts and warnings. Considering the fact that every day 1.6 million children are home (U.S. Census Bureau 1994; Phillips and Hewett 2005) this is an important research gap.

Race and Ethnicity. Considerable research has focused on the effects of culture on receiving and responding to warning messages. Racial and ethnic minorities are less likely to accept a warning message as credible without confirming it with other sources, such as family and social networks, often delaying reaction (Fothergill et al. 1999; Lindell and Perry 2004). After the 1989 Loma Prieta earthquake, for example, Hispanics were more likely to have secured information from family and friends while Anglos relied on formal English-language sources (Phillips and Ephraim 1992). Researchers studying the 1995 F5 tornado in Birmingham found that fewer African Americans used television as their primary information source. African American and Hispanic households were less likely to evacuate for Hurricane Andrew (Gladwin and Peacock 1997).

While this tendency to confirm and delay has been substantiated in numerous studies, it is important to recognize that differences exist among and within minority groups. For example, in one study Mexican Americans reported using social networks to confirm information more often than African Americans. (Perry and Mushkatel 1986; see also Blanchard-Boehm 1997).

Further, each population carries internal diversity: being Hispanic may mean that one's cultural framework for interpreting a warning message derives from Spain, Puerto Rico, Mexico, South America or the Philippines. Some racial and ethnic differences in disaster response can be explained by other conditions such as poverty or geographical location in hazardous areas, but even when these factors are isolated, cultural differences appear to be an important factor related to warning messages (Lindell and Perry 2004).

However, more qualitative and quantitative research is needed to better explain how race and ethnicity interacts with other variables as a first step toward targeted weather-related messages.

Gender. Gender has increasingly been recognized as a vulnerability factor, spurred by a critical wave of research and producing a core of dedicated scholars. Several key books, special journal issues, articles, conferences and a web site have resulted (Gender and Disaster Network 2005). Gender often works indirectly to affect disaster response. For example, the majority of single parents are female and approximately $40 \%$ have household incomes below the poverty line. It is not surprisingly that many single mothers report difficulties in being able to respond effectively to hurricane warnings by preparing their homes and/or evacuating (Morrow and Enarson 1999). Gender roles often place women and men in locations that influence their vulnerability. For 
example, all of the women in the coastal village of Lampuuk, Indonesia were killed by the tsunami on December 26, 2004 while children at school and men fishing at sea were spared (Times Online 2005).

Additional Factors. In the 1990s research attention expanded to include a wider range of high risk groups, including persons with disabilities, tourists, the homeless, farmworkers and immigrants (National Organization on Disability, n.d.; Peacock, Morrow and Gladwin 1997; Enarson and Morrow 2000; Drabek 1994; Phillips et al. 1994; Phillips 1996 and 1993). Most of this work focuses on disaster impact and recovery rather than on how these groups receive, interpret and respond to warnings.

Complex Interactions. What makes vulnerability research especially complex is that it is extremely difficult to disentangle the effects of one population characteristic from another (Tierney et al., 2001). It is hard, for example, to separate how culture influences warning receipt from the influences of gender or age. Further, vulnerability factors tend to cluster, multiplying the risk of certain segments of the population. To illustrate the intersection of one variable (age) with another (disability) consider the situation of a Sri Lanka shelter for physically disabled and mentally ill children where $60 \%$ of the residents perished (Torchia 2005). After Hurricanes Bonnie, Dennis and Floyd, researchers found that evacuation compliance among persons with disabilities was influenced by not only poverty, but social isolation and educational level (Willigen et al. 2002).

New Technologies. Another issue to be considered when targeting high-risk populations is the rapid pace at which new communication technologies are becoming available. As one example, text messaging surfaced as a key information source after September $11^{\text {th }}$. Warning messages can now be delivered directly to individuals through cell phones and personal data assistants. Little is known about how age, culture, and gender affect their use. Due to the expense, such new technologies are apt to exacerbate the axiomatic effect of socioeconomic status on the timely receipt of warnings.

To summarize, the research literature on warning messages and vulnerable populations is increasing. However, much of the work to date lacks sufficient depth and breadth to provide reliable guidance to forecasters and emergency managers. The good news is that a skilled network of social science researchers is interested in working on this topic. The timing could not be better. Many communities, recognizing the problems of high-risk populations, have established special needs registries and buddy systems, developed programs and practices targeting specific groups, and supplied special emergency equipment. It is possible, however, that these good intentions are not based on sound scientific research.

\section{KEY CONCEPTS FROM SOCIAL SCIENCE VULNERABILITY RESEARCH}

The ultimate goal of communicating forecasts, watches and warnings is to motivate individuals to take appropriate action. However, before they do so, most persons move through a multistage decision-making process. Researchers characterize the process using a variety of terms, but in general messages need to be heard and attended to, a process that requires comprehension and, quite frequently, confirmation. For action to occur, the recipient must believe that protective action is necessary and possible. The message must be personalized in order to motivate the desired behavioral response (Lindell and Perry 2004; Mileti 1999). 
People often wait to act while confirming the message (Mileti 1999). Studies over the last two decades have identified population differences in the sources various groups tend to turn to for confirmation information. However, a clear finding is that social networks are critical resources for confirming the personal relevance of a message. This appears to be especially true for women and some racial and ethnic groups (Fothergill et al. 1999; Fothergill 1999). Getting those at risk to heed forecasts and warnings, then, requires tapping into those social networks (Heinz Center 2002). Research needs to further examine confirmation behavior and how social networks can be used to increase warning effectiveness.

If we want people to heed risk communications, then "warning messages must mean something to them" (Handmer 2002). To illustrate, there is considerable evidence that women are more likely to believe warnings, to warn others, and to want to respond. (See Major and Atwood 2004 for a recent example.). Researchers have theorized that meaningfulness based on gender is influenced by female socialization patterns; in particular norms compelling women to obey authority and to bear responsibility for the family (Morrow and Enarson 1999). Because gender may positively influence warning response, women represent a potential key target for public outreach and education. Conversely, if men tend toward riskier behaviors, it is important to find effective ways to reach and educate them to respond to warnings. For both genders, cultural values and norms appear to influence interpretation of forecasts and warnings, suggesting a promising research agenda. However, it is not appropriate to launch one-dimensional studies based on gender, or any other attribute. Warning response is likely to involve a combination of gender, race, income and family structure factors.

Useful research must thus understand behavioral response within a complex array of structural and situational variables. Language, literacy, household status, family status and recent immigration represent promising situational variables for future research (Heinz Center 2002). For example, research on racial and ethnic families, though limited, suggests that Mexican Americans may wait to take action until the entire family has been gathered, a behavioral pattern resulting from culturally-based values on the importance of the family. It takes longer for large families to respond, and minority families are more likely to be multi-generational. A family that has recently arrived in the U.S. may face a frustrating series of walls between safety and critically needed information.

The credibility of the sender of the warning message is central to motivating behavior. Credibility is based in part on trust. (Tierney et al. 2001; Mileti 1999). Trust emerges through sustained relationships between the receiver and sender. For example, people tend to gravitate to specific broadcast meteorologists with whom they feel a connection. Research suggests that differences between sender and receiver may impede transmission. Shared cultural backgrounds can serve as a basis for making social connections and building relationships. Though researchers have recommended that consistent messages be transmitted through multiple, credible sources in order to reach a variety of different groups, social science has failed to adequately identify strategies for building credibility and social relationships between senders and receivers of warning messages.

There is no evidence that research on at-risk populations is reaching students of meteorology, broadcast journalism and emergency management. Within emergency management, courses on populations at risk, such as the Social Vulnerability one in FEMA's higher education curriculum (FEMA n.d.), are often considered an elective even though they clearly represent core information that may enable future professionals to save lives. Anecdotally, we often find 
ourselves talking back to television broadcasters, "tell them to call Grandma!" or "have them check on their neighbor kids home alone” or "turn around and face the camera." An easy intervention might be to research degree programs and promote curriculum transformation projects based on social science research.

\section{RESEARCH NEEDS}

To understand fully the depth and breadth of forecasting and warning as it applies to vulnerable populations calls for a wider variety of methodological strategies. It is clear that research remains insufficient, incomplete, and at times contradictory. Of paramount importance is more thorough coverage of differences both across and among population groups. Further, exploring the complex array of issues requires a range of research designs including panel studies, cohort analyses and longitudinal assessments. Each technique enables us to capture insights into the realities, complexities and changes that occur over time.

The traditional quantitative deductive model of science, while generative of much useful work, has been critiqued as missing the rich context in which people live. Much of the existing disaster research, especially research on vulnerable populations, is qualitative in order to capture the context that can be missed in quantitative work. Conversely, qualitative disaster research has been critiqued as too heavily oriented toward one-shot case studies. Future qualitative research should include appropriate levels of funding for both multiple, comparative case studies as well as the deep insights generated by ethnographic studies. Deductive work that systematically operationalizes key concepts and measures specific variables and testable hypotheses must be generated as well. Complex, multivariate statistical models are essential to understanding the interplay of multiple factors related to how various at-risk groups receive and respond to warning messages. In short, we need to employ a full range of methods to collect the data needed to better protect high-risk groups.

Further, research on vulnerable populations requires skilled, thoughtful, often creative sampling since so many vulnerable populations (immigrants, the homeless, non-English speaking) are missed by standard sources (Skerry 2000). Indeed, sampling may require the assistance of those closest to the affected populations such as social service providers, caretakers, neighborhood leaders, linking organizations, and advocacy groups.

Field researchers have debated the "insider-outsider" approach to sampling and research (Baca Zinn 1979). Involving those within a population in the research project presumably heightens insights, provides potential cultural contextual information, and opens doors normally closed to outsiders. Yet, research with or from the perspectives of those most affected continues to be rare (Gottfried 2000).

One alternative is to urge new research traditions. Participatory action research links to and empowers insiders in locally relevant research (Smith et al., 1997; Greenwood and Levin 1998; Stringer 1999). Approaches that link researchers and practitioners to key community leaders hold promise (Andrews 2001). Involving stakeholders in both applied and basic research projects has initiated fruitful dialogue although efforts must be made to carefully involve the "voice of less powerful community members (women, youth, non-landowners) in risk management decisionmaking” (Cronin et al. 2004). 


\section{BROADER ISSUES}

Emergency management students frustrated by the massive challenges that confront them often question who bears responsibility for social vulnerabilities. For example, increasing evacuation compliance among those with disabilities requires tackling massive social problems such as poverty and social isolation. Emergency managers cannot be expected to tackle the root causes of vulnerability. However, at a bare minimum they need to identify the vulnerabilities and capacities of high-risk groups within their jurisdictions. They may find that identifying leaders and building coalitions can help reach vulnerable populations with effective warning messages.

Some authors advocate engaging communities in deciding what constitutes risk (Mileti 1999). Research on vulnerable populations suggests that we as a society have already made those choices by permitting vulnerabilities to develop and linger. Tackling the problems that underlie social vulnerabilities requires linkages among researchers, practitioners and policymakers. Making vulnerable populations safer means that we cannot work in isolation-we must connect to agencies and businesses. Construction firms need to be convinced to provide safe rooms and mobile home park operators urged to provide shelters, as examples. Combining research with action must be the driving focus of social science research that addresses vulnerability.

\section{RECOMMENDATIONS FOR FUTURE SOCIAL SCIENCE RESEARCH}

- Initiate comprehensive and comparative examination of how various populations receive and interpret forecasts and warnings. Encourage longitudinal studies to track changes within and across populations. Possible topics might include:

o Understanding how the elderly receive and interpret warning messages;

o Exploring ways to reach children home alone;

o Documenting differences in preferred warning information sources among various sectors of the population;

o Exploring the use of new technologies in warning special needs groups.

- Examine the interaction of demographic variables such as age, race and ethnicity, gender, income, and education on receipt, interpretation and use of forecasting and warning information.

- Examine the interaction of situational and cultural contexts on the receipt, interpretation and use of forecasting and warning information. Possible topics might include:

o Understanding the role of isolation among vulnerable groups;

o Documenting the influence of household structure on warning compliance;

o Exploring how social networks can promote warning compliance.

- Promote research focusing on rarely examined populations such as persons with disabilities, the homeless, Native Americans, persons in institutions or congregate care facilities, farmworkers, recent immigrants and mobile home residents. 
- Research the content of educational programs in emergency management, meteorology, broadcast journalism and relevant social and physical sciences to determine if content on vulnerable populations is being disseminated.

- Encourage research that utilizes cultural traditions and folk knowledge to promote warning compliance.

- Involve "insiders" from underrepresented populations to participate in the research and dissemination efforts.

- Explore ways to increase the credibility of forecasters and broadcast meteorologists among various vulnerable groups.

- Assess the extent to which organizations involved in issuing forecasts and warnings have diversified their own staff to better understand and relate to vulnerable groups within their communities.

- Identify best practices for community outreach to high-risk groups.

- Identify the most effective ways to personalize and target messages.

- Explore ways in which forecasting and warning agencies can tap into social networks to enhance appropriate behavioral response.

- Document how various populations make evacuation decisions.

- Explore fully how and why at-risk populations engage in confirmation behavior as well as the timing and effects on warning compliance.

- Promote a full range of research designs, including multivariate quantitative work and a variety of qualitative approaches, utilizing rigorous sampling procedures.

- Encourage multidisciplinary research as a way to leverage funding and to drive more broadly applicable research.

- Join other organizations to fund and research comprehensively the full range of populations at risk and the ways in which demographic, situational and structural variables intermingle and overlap.

- Engage more broadly all of the social sciences: economics, political science, geography, political science and sociology in research to improve warning messages. 


\section{REFERENCES}

- For an extensive bibliography on the full range of vulnerabilities and a complete set of references, visit http://training.fema.gov/emiweb/edu/completeCourses.asp. Select Social Vulnerability course and then open the Bibliography.

- For thorough literature reviews on gender, race and ethnicity and poverty, see the work under Fothergill listed below.

Aguirre, Ben et al. Sarasota, Texas, tornado May 22, 1987. Washington DC: National Academy Press.

Andrews, Jill H. 2001. "Safe in the 'Hood: earthquake preparedness in midcity Los Angeles." Natural Hazards Review 2/1: 2-11.

Baca Zinn, Maxine. 1979. "Field Research in Minority Communities: Ethical, Methodological, and Political Observations by an Insider." Social Problems 27/2.

Barnartt, Sharon and Richard Scotch. 2001. Disability Protests: contentious politics 19701999. Washington D.C.: Gallaudet University Press.

Bell, B.D. et al. 1978. "Service utilization and adjustment patterns of elderly tornado victims in an American disaster.” International Journal of Mass Emergencies and Disasters 3: 71-81.

Blanchard-Boehm, Denise. 1997. "Risk Communication in Southern California: ethnic and gender response to the 1995 revised, upgraded earthquake probabilities.” Quick Response Report, Natural Hazards Research and Applications Information Center.

Cronin, Shane J. et al. 2004. "Maximising multi-stakeholder participation in government and community volcanic hazard management programs; a case study from Savo, Solomon Islands.” Natural Hazards 33: 105-136.

Drabek, T.E. 1994. Disaster Evacuation and the Tourist Industry. Program in Environment and Behavior Monograph no. 57, Institute of Behavioral Science, University of Colorado, Boulder, Colo.

Enarson, Elaine. 2004. Social Vulnerability Course, FEMA Higher Education Project. http://training.fema.gov/emiweb/edu/completeCourses.asp

Enarson, Elaine 2001. "What women do: gendered labor in the Red River Valley flood." Environmental Hazards 3: 1-18.

Enarson, Elaine and Betty Hearn Morrow, editors. 1998. The Gendered Terrain of Disaster: through women's eyes. Miami, FL: International Hurricane Center.

Fothergill, Alice and Lori Peek. 2004. "Poverty and disasters in the United States: a review of recent sociological findings.” Natural Hazards 32: 89-110.

Fothergill, Alice. 1996. “Gender, Risk and Disaster.” International Journal of Mass Emergencies and Disasters 14/1: 33-56. 
Fothergill, Alice, Enrique G.M. Maestas and JoAnne DeRouen Darlington. 1999. "Race, ethnicity, and disasters in the United States: a review of the literature.” Disasters 23/2: 156173.

Gender and Disaster Network. http://online.northumbria.ac.uk/geography_research/gdn/ Includes a list of researchers and an extensive bibliography on gender and disasters.

Gladwin, Hugh and Walter Gillis Peacock. 1997. "Warning and Evacuation: A Night for Hard Houses.” Pp. 52-74 in Peacock, W.G., Morrow, B.H. and Gladwin, H. Hurricane Andrew: Ethnicity, Gender and the Sociology of Disasters. Miami, FL: International Hurricane Research Center, Florida International University.

Gottfried, Heidi, editor. 1996. Feminism and Social Change: bridging theory and practice. Urbana, IL: University of Illinois Press.

Greenwood, Davydd J. ad Morten Levin. 1998. Introduction to Action Research: social research for social change. Newbury Park, CA: Sage.

Handmer, John. 2002. “Are Flood Warnings Futile? Risk communication in emergencies.” Australiasian Journal of Disaster and Trauma Studies http://www.massey.ac.nz/ trauma/issues/2000-2/handmer.htm, accessed January 10, 2005.

Legates, David R. and Matthew D. Biddle. 1999. "Warning response and risk behavior in the Oak Grove Birmingham, Alabama Tornado of 08 April 1998.” Quick Response Report \#116, Natural Hazards Research and Applications Information Center.

Lindell, Michael K., and Ronald W. Perry. 2004. Communicating Environmental Risk in Multiethnic Communities. Newbury Park, CA: Sage.

Major, Ann Marie and L. Erwin Atwood. 2004. "Assessing the usefulness of the U.S. Department of Homeland Security's Terrorism Advisory System.” International Journal of Mass Emergencies and Disasters 22/2: 77-102.

Mileti, Dennis. 1999. Disasters by Design. Washington D.C.: Joseph Henry Press.

National Organization on Disability. 2004. "Emergency Preparedness Survey.” Available at http://www.nod.org, accessed January 10, 2005.

Peacock, Walter Gillis, Betty Hearn Morow and Hugh Gladwin. 2000. Hurricane Andrew: ethnicity, gender and the sociology of disasters. Miami, FL: International Hurricane Center.

Peterson Lisette, et al. 1986. “Mom or dad says I shouldn’t: Supervised and unsupervised children's knowledge of their parents' rules for home safety.” Journal of Pediatric Psychiatry 11(2): 177-188.

Peterson Lisette et al. 1988. “Community interventions in children's injury prevention: Differing costs and differing benefits.” Journal of Community Psychology16: 188-204.

Perry, Ron and Alvin Mushkatel. 1986. Minority Citizens in Disasters. Athens, GA: University of Georgia Press.

Phillips, Brenda D. 1996. "Homelessness and the Social Construction of Places: the Loma Prieta Earthquake.” Humanity and Society 19/4: 94-101.

Phillips, Brenda D. 1993. “Cultural Diversity in Disaster." International Journal of Mass Emergencies 11: 99-110. 
Phillips, Brenda and Mindy Ephraim. 1992. "Living in the Aftermath: blaming processes in the Loma Prieta earthquake.” Working Paper No. 80, Natural Hazards Research and Applications Information Center.

Phillips, Brenda D., Lisa Garza and David M. Neal. 1994. "Intergroup Relations in Disasters: service delivery barriers after Hurricane Andrew.” Journal of Intergroup Relations 21: 1827.

Phillips, Brenda D. and Paul L. Hewett. 2005. "Home Alone: disaster, mass emergencies, and children in self-care.” Journal of Emergency Management 3/2: 31-35.

Rossman, Gretchen B. and Sharon F. Rallis. 2003. Learning in the Field: an introduction to qualitative research, second edition. Newbury Park, CA: Sage.

Skerry, Peter. 2000. Counting on the Census: Race, Group Identity, and the Evasion of Politics. Washington DC: The Brookings Institution.

Smith, Susan E., Dennis G. Willms and Nancy A. Johnson. 1997. Nurtured by Knowledge: learning to do participatory action-research. Ottawa, Canada: The Apex Press.

Stringer, Ernest T. 1999. Action Research, second edition. Newbury Park, CA: Sage.

Tierney, Kathleen, Michael K. Lindell and Ronald W. Perry. 2001. Facing the Unexpected. Washington D.C.: National Academy Press.

Times Online. 2005. “The town left without women.” Accessed 1/12/2005 at http://www.timesonline.co.uk.

Torchia, Christopher. 2005. “Disabled children lay helpless during flood.” Associated Press, January 2, Tulsa World, p. A14.

U.S. Bureau of the Census. 1994. Who's Minding the Kids? SB/94-5, issued April 1994.

Willigen, Marieke Van, Terri Edwrds, Bob Edwards and Shawn Hessee. 2002. "Riding out the storm: experiences of the physically disabled during Hurricanes Bonnie, Dennis and Floyd." Natural Hazards Review 3/3: 98-106.

Wood, Vincent T. and Robert A. Weisman. 2002. "A hole in the weather warning system: improving access to hazardous weather information for deaf and hard of hearing people." American Meteorological Society, 187-194. 